Acta Agroph., 2019, 26(3), 43-55

doi: $10.31545 /$ aagr/114987

\title{
EFFECT OF A MAGNETIC FIELD ON WATER DESORPTION FROM THE SURFACE OF POTATO STARCH*
}

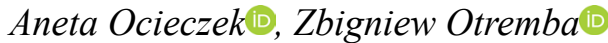 \\ Department of Commodity Science and Quality Management, Gdynia Maritime University \\ Morska 81-87, 81-225 Gdynia, Poland \\ e-mail: a.ocieczek@wpit.umg.edu.pl
}

\begin{abstract}
In this work we describe the kinetics and the extent of water desorption from the surface of natural organic particles under conditions of a magnetic field, with magnetic induction exceeding a thousand times the induction of a geomagnetic field. The scope of the present study included a comparative analysis of the kinetics and the extent of water vapour desorption under natural conditions and in an artificially-created magnetic field. The research material were potato starch particles that were characterized in terms of grain size. The results of the study showed that the impact of a strong magnetic field significantly affects both the kinetics of the process of water vapour desorption as well as its extent. Regardless of the test temperature, the magnetic field effect increased the kinetics and extent of the phenomenon under study. Starch particles dehydrated more rapidly and deeper under the influence of a strong magnetic field. This fact enables us to state that under conditions different than those occurring on the Earth's surface, the storage stability of organic particles will be significantly different from those observed in Earthlike conditions. This, in turn, may contribute to a radical change in the durability of food found in such conditions. The result of this experiment also raises hopes for the use of magnetic fields to reduce the costs associated with energy-intensive drainage processes. This may be of particular importance when dewatering substances sensitive to high temperatures. The results achieved also point to the feasibility of increasing the functional effectiveness of the facilities used for the dehydration of products sensitive to high temperatures.

Keywords: magnetic field, increase in desorption kinetics, increase in the extent of desorption, food durability in extraterrestrial conditions
\end{abstract}

\section{INTRODUCTION}

The storage stability of food products is an issue of concern in the global economy. The inability to efficiently and effectively extend the shelf life of food leads to its waste, and also to contamination of the natural environment as a result of intense

* Work conducted from funds of the Gdynia Maritime University for scientific activity WPiT/2019/PZ/05 
food production. These issues may lead to serious social problems associated with the management of material goods and their trade turnover. In addition, considering the development of technology, including space technology, it may be assumed that new problems will emerge with regard to the storage of food products involving the adequate stability of food supplies under extraterrestrial conditions. The necessity of providing conditions that would allow a human to remain away from the Earth for long periods, initially on its natural satellite, will be a real challenge in the near future. The ability to inhabit the surface of the moon will be the first step and a milestone in space exploration. The search for innovative solutions allowing for the exploration of space is an issue that cannot be neglected (www.esa.int). This need includes several factors that are important in the task of sustaining human life. The first one is the need to develop optimized technologies and systems that will support future space exploration. The second factor is the search for resources that will help to eliminate the scarcity of resources on the Earth and allow for sustainable development (www.esa.int). The third important factor is the potential threat posed by the presence of asteroids and comets on a collision course with the Earth (www. crazynauka.pl), the impact of which may cause adverse changes to its natural environment (www2.jpl.nasa.gov).

The colonization of the Moon seems inevitable (www.tech.wp.pl), and this poses problems related to life support systems in the extraterrestrial environment. One such problem is the provision of food for the members of the manned missions. A question arises in this context, as to whether the food brought from Earth will be as stable as it is on Earth. The Moon has neither an atmosphere, nor a magnetic field generated by its core (www.encyklopedia.pwn.pl), and the intensity of the gravitational field is significantly weaker than that of Earth. In the light of these differences, the question arises as to whether a magnetic field has any impact on the course of surface phenomena, such as drying / desorption, which occur on the surface of organic matter and which may affect its storage stability.

Surface phenomena affect both the kinetics and intensity (kinetics + range) of many physical, physicochemical, chemical, biochemical, and microbiological processes. These, in turn, determine the storage stability of food (Rahman 2006, Ocieczek et al. 2015). One natural and commonly occurring phenomenon is the drying of biological matter, the essence of which is water desorption from its surface to the environment. This phenomenon involves the release of water into the environment when two interacting centres tend towards a state of dynamic equilibrium.

Studies concerning the kinetics of water vapour sorption by selected food products (Lewicki et al. 1977) have already shown that the effect of the relative humidity of the atmosphere on the phenomenon of sorption depends on the physical and chemical properties of the sample. Starch is characterized by relatively high homogeneity in terms of its chemical composition and physical structure. 
The phenomenon of sorption proceeds on its surface with high intensity, which is caused by the high concentration of sorption centres with a similar energy level (Lewicki et al. 1977). The course of the sorption phenomenon on the surface of the starch does not reveal a change in mechanism, which is associated with the semicrystalline, ordered structure of starch granules (Ocieczek 2013). The kinetics of the sorption process depends on the difference in water vapour pressure between the sample and its environment (it can be positive or negative), but it always decreases when this difference diminishes.

To date, magnetic fields have been shown to affect various biological and physicochemical processes, which have been used, in particular, in the field of environmental engineering - for example, in the crystallization of calcium carbonate (Fathi et al. 2013), water purification (Ambashta and Sillanpää 2010), coagulation and sedimentation of colloid particles (Higashitani 1996, Wang et al. 1994), and in the treatment of wastewater (Wang et al. 2010, Zhang et al. 2011). Other research has confirmed the effect of magnetic fields on the dynamics of certain reactions occurring in food during its storage (Kędzierska-Matysek et al. 2018) as well as on the appropriate functioning of living organisms (Fey et al. 2019).

However, to date, no studies have been performed which address the influence of magnetic fields on the course of surface phenomena. Therefore, research was undertaken to assess the effect of a strong, stable magnetic field on the course of a surface phenomenon, expressed as water vapour desorption by the matrix of a solid body - in this case: potato starch. The results achieved were expected to help to verify the hypothesis that the effect of the application of a magnetic field results in a change in the thermodynamic state of water molecules found in potato starch, as a result of which, the process of their desorption takes place with a different intensity than when starch granules are only exposed to the geomagnetic field. The adopted assumption stemmed from previously presented assumptions and from the inability to carry out an experiment under Earth conditions simulating the conditions prevailing on the Moon due to the constant impact of the geomagnetic field. Therefore, in experimental conditions, the study was carried out in a stronger field than the geomagnetic one, and the results obtained formed grounds for verifying the hypothesis and became the starting point for predicting differences in the course of desorption in the absence of a magnetic field, as is the case on the Moon.

The concept of studying the phenomenon of water desorption from starch granules was conceived for several reasons. The first is the strategic importance of starch in human nutrition. Starch is the basic source of energy for the human body. In the case of the colonization of the Moon and the first manned missions designed to maintain a human presence on the satellite, starch will certainly be the basic raw material used for feeding crews. Native starch is stable under terrestrial conditions. However, there is no information as to how it will behave under magnetic field 
conditions with significantly lower induction. As a consequence, it is difficult to predict a likely scenario of events. Of course, it would also be interesting to study this phenomenon using the example of a sample of another pure ingredient (e.g. protein in the form of gelatin), followed by samples with a complex composition. The second important reason for studying the phenomenon of water desorption under the conditions of a strong constant magnetic field was the assumption that this field has a significant effect on the course of desorption/drying phenomenon. One particularly interesting aspect of the study was the determination of the effect of the magnetic field on the kinetics and desorption range. This assumption resulted from the search for methods that would reduce the energy consumption and time consumption of the drying process. Thus, the research idea was in line with the concept of sustainable development and the protection of natural resources.

\section{MATERIAL AND METHODS}

The experimental material included potato starch produced under industrial conditions by Przedsiębiorstwo Przemysłu Spożywczego PEPEES S.A. (Łomża, Poland). It was in the form of fine-grain white powder.

The particle-size characteristics of potato starch, including particle size and shape distribution, were determined using a Morphology G3 automatic analyser (Malvern Instruments), which enables measurements of distributions of solid particles with sizes ranging from 0.5 to $10,000 \mu \mathrm{m}$. The results of these analyses include the numeric distributions of such parameters as: diameter, circularity, convexity, elongation, aspect ratio, and solidity.

The initial water content of the material was determined using the thermal drying method with a UE 400 laboratory convective dryer (Schutzart). Ca. $1 \mathrm{~g}$ of potato starch was weighed with an accuracy of $0.0001 \mathrm{~g}$ into a previously weighed weighing bottle. Next, the bottles were placed in a dryer and dried at a temperature of $105^{\circ} \mathrm{C}$ until a constant weight was achieved. The determination was conducted in three parallel replications. The water content $(x)$ was computed based on equation (1) and expressed in grams per 100 grams of dry matter:

$$
x=\frac{(b-c) 100}{c-a}
$$

where: $a$ - bottle weight $(\mathrm{g}), b$ - weight of a bottle with a weighed portion of the product $(\mathrm{g}), c$ - weight of a bottle with a weighed portion of the dried product $(\mathrm{g})$.

Water activity $\left(\mathrm{a}_{\mathrm{w}}\right)$ at a temperature of $20^{\circ} \mathrm{C}$ was determined with a precision of \pm 0.003 using an AquaLab apparatus (Version AS4 2,14.0 2017, Series 4TE and 4TEV, Decagon Devices, Inc., Pullman, WA, USA). 
A stable heterogeneous magnetic field was induced by using two neodymium permanent magnets placed $10 \mathrm{~cm}$ away from each other. The magnetic field induction distribution and location of the weighing bottles with potato starch samples in the magnetic field are presented in Figure 1.

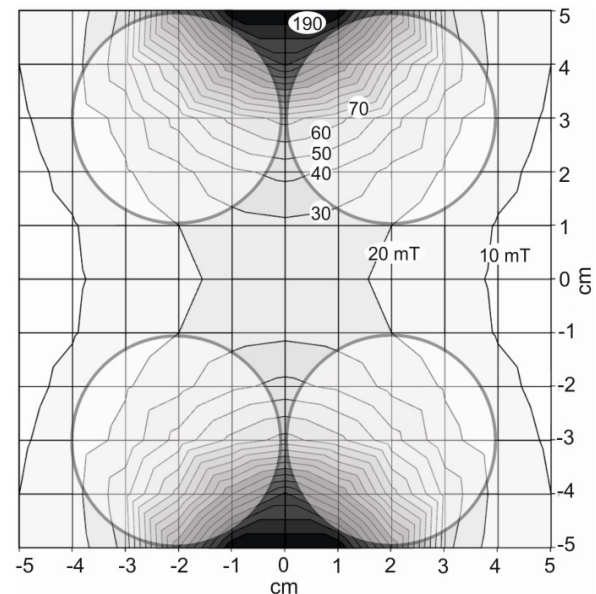

Fig. 1. Magnetic field induction distribution and location of weighing bottles with samples of potato starch.

The kinetics of water vapour desorption from the analysed samples was determined based on the extent and rate of change in sample weight over time. The sample weight changes were determined based on changes in the water content of the samples, using the gravimetric method. The rate of change in the weight of the starch samples tested was determined as the quotient of change in the weight of the samples tested (always from the initial state) over time. Measurements were performed in time intervals of 1.5, 3.0, and 4.5 per hours, using a WAS 100/X laboratory scale (RADWAG). Water desorption was induced by placing the samples in a UE 400 laboratory convective dryer (Schutzart) at two temperatures: $30 \pm 1^{\circ} \mathrm{C}$ or $40 \pm 1^{\circ} \mathrm{C}$. The stability of the work parameters of the dryer over time were controlled based on the indications of electric thermometers, which are integral parts of the dryer, and expansion thermometers mounted inside the drying chamber. In addition, during the collection of samples for their weight measurement, water vapour pressure was measured in the drying chamber (set at a temperature of $30 \pm 1^{\circ} \mathrm{C}$ or $40 \pm 1^{\circ} \mathrm{C}$ ) using an LYWSDCGQ hygrometer (Xiaomi Mijia, China). The temperatures used in the study were selected in such a way that they could be considered high enough to accelerate the desorption process, and at the same time sufficiently low that they would not mask the possible impact of a constant, heterogeneous magnetic field on any phenomenon that has not been identified and described to date. In the next stage of research concerning the influence of magnetic fields on 
the course of desorption/drying, the effect of constant and homogeneous magnetic fields on the course of desorption from the surface of various organic samples at $20^{\circ} \mathrm{C}$ for a longer time will be assessed.

Four starch samples (ca. $1 \mathrm{~g}$ ) were prepared for analysis in glass vessels (width: $35 \mathrm{~mm}$, height: $30 \mathrm{~mm}$ ) with hermetic glass-ground stoppers, that were placed in a dryer at the same distance from each other (Fig. 1). Analyses were carried out for the samples prepared under control conditions $(\mathrm{CC})$ and those maintained under conditions of exposure to magnetic fields (MF), by placing the respective samples on two separate shelves of the dryer, and drying them at a temperature of $30^{\circ} \mathrm{C}$. Next, analyses were conducted at a temperature of $40^{\circ} \mathrm{C}$ for a new batch of $\mathrm{CC}$ and MF samples. The starch samples were collected directly from a hermetically sealed glass vessel. Each of the experimental variants was repeated twice, however, in the first iteration the sets of control samples were placed in the bottom shelf of the dryer, whereas in the second one - they were placed on the upper shelf of the dryer. The results reported in this manuscript represent an arithmetic mean of eight measurements.

The significance of differences in water content between the samples, after their incubation under control conditions and under exposure to conditions of the stable magnetic field for the same time intervals, was evaluated using the Student's t-test. Previously, the samples were subjected to variability evaluation (variance analysis) with the Fisher's test.

\section{RESULTS AND DISCUSSION}

The potato starch used in the study was a mixture of particles differing in terms of sizes and shapes, which may potentially be of importance to the course of the desorption process. Therefore, the granulometric characteristics of the powder were determined and the respective results are presented in Table 1.

Table 1. Selected physical characteristics of potato starch

\begin{tabular}{lcccccc}
\hline & \multicolumn{6}{c}{ Parameter } \\
\cline { 2 - 7 } & Min. & Max. & Mean \pm SD & D [n, 0.1] D [n, 0.5]D [n, 0.9] \\
\hline Number distribution of diameter $(\mu \mathrm{m})$ & 1.090 & 175.03 & $23.14 \pm 14.17$ & 7.98 & 19.99 & 42.15 \\
Number distribution of circularity & 0.018 & 1.000 & $0.870 \pm 0.186$ & 0.575 & 0.956 & 0.990 \\
Number distribution of convexity & 0.357 & 1.000 & $0.978 \pm 0.056$ & 0.898 & 0.994 & 0.998 \\
Number distribution of elongation & 0.000 & 0.931 & $0.225 \pm 0.157$ & 0.045 & 0.195 & 0.452 \\
Number distribution of aspect ratio & 0.069 & 1.000 & $0.775 \pm 0.157$ & 0.546 & 0.803 & 0.952 \\
Number distribution of solidity & 0.161 & 1.000 & $0.967 \pm 0.081$ & 0.845 & 0.997 & 0.999 \\
\hline
\end{tabular}

Counted particles $n=85$ 723; Min. - minimum value; Max. - maximum value; Mean \pm SD - mean value \pm standard deviation; $\mathrm{D}[\mathrm{n}, 0.1]$ - for $10 \%$ of the particles the value of the parameter is lower than that displayed in the cell of table $1 ; \mathrm{D}[\mathrm{n}, 0.5]$ - for half of the particles the value of the parameter is lower than that displayed in the cell of Table $1 ; \mathrm{D}[\mathrm{n}, 0.9]$ - for $90 \%$ of the particles the value of the parameter is lower than that displayed in the cell of Table 1. 
Figure 2 depicts the size distribution of the starch particles. The distribution includes equivalent diameters, because a large number of particles had no spherical shape, as shown in Figure 3.

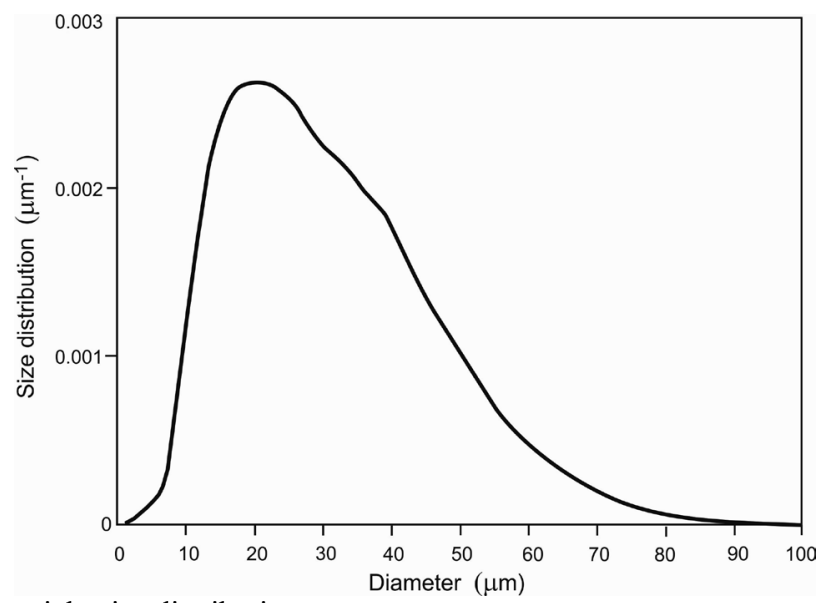

Fig. 2. Starch particle-size distribution.

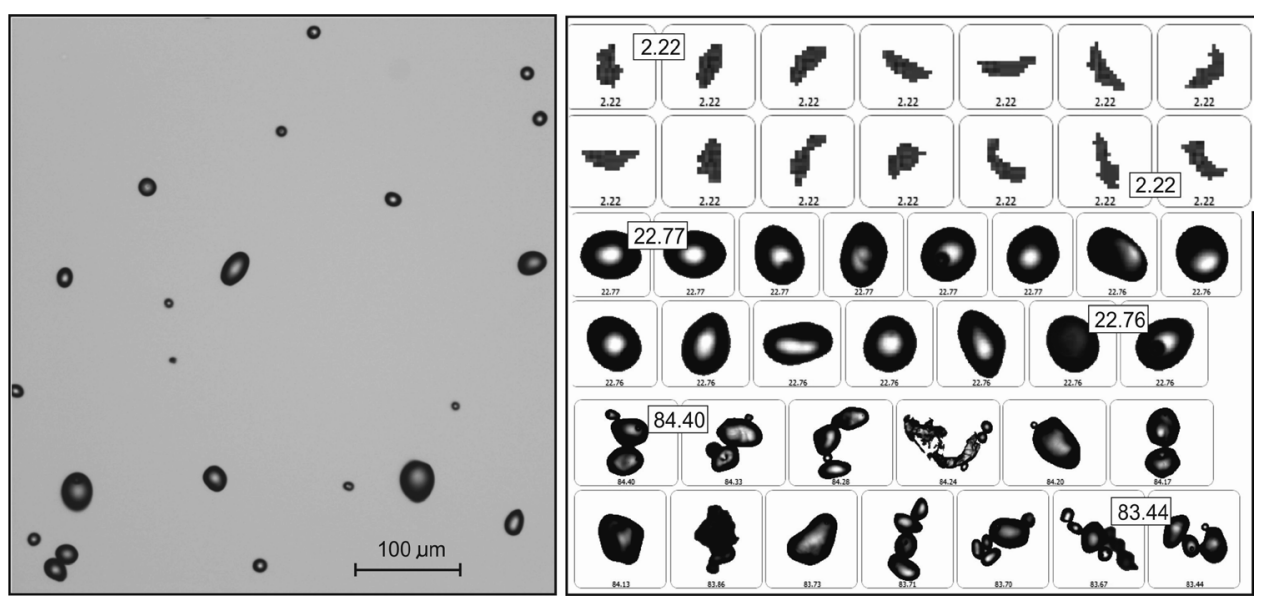

Fig. 3. Fragment of a microscopic image of starch powder (left) and starch particles in the range of small, dominant and large diameters (right).

The sorption properties of the powders, including their susceptibility to dehydration, are determined by multiple interactions that proceed between the surface of the body being dehydrated and the environment surrounding it. The most significant factor in this case is the water content of the product, followed by interactions between hydrophilic groups on the surface of the body and water molecules, the phenomenon of water vapour condensation in capillaries, and finally the concentration and type of water-soluble substances (Czerniawski and Michniewicz 1998). 
The initial water content of potato starch samples reached $18.895 \mathrm{~g} \mathrm{H}_{2} \mathrm{O} 100 \mathrm{~g}^{-1}$ d.m., with a standard deviation of $0.422 \mathrm{~g} \mathrm{H}_{2} \mathrm{O} 100 \mathrm{~g} \mathrm{~g}^{-1} \mathrm{~d}$.m. In turn, the mean water activity of the samples was at $0.5063 \pm 0.0060$. The mean pressure of water vapour in the atmosphere of the drying chamber, which was set at a temperature of $30 \pm 1{ }^{\circ} \mathrm{C}$ was $35.93 \pm 2.23 \%$, whereas in the chamber with a temperature of $40 \pm 1{ }^{\circ} \mathrm{C}$ it was $15.5 \pm 0.95 \%$.

Due to the difference between the initial water activity in the potato starch samples and the water vapour pressure in the drying chamber, the system was subjected to step excitation and tended to achieve a state of equilibrium, this was reflected in the decreased rate of sample weight change (Figs 4 and 5). Reaching the equilibrium state corresponded to reaching the upper limit available for the set parameters in the dryer. A disturbance in the course of the results registered in the rate changes in Figure 4, and may be explained by an accidental factor that was not precisely identified during the experiment. However, it may be assumed that the most probable reason was the heterogeneity of the tested material. It should be emphasized that each experimental point was designated as a separate study, in which material was taken from the packaging and dried at a given time. Such a deviation could not take place if all of the measurements at particular time intervals were carried out on the same samples. The procedure adopted in the described experiment was aimed at obtaining results that allow for the verification of the adopted assumption, taking into account the greatest variability of environmental factors, and thus recognizing the phenomenon in the least favourable conditions that could mask its existence.

In both measuring series (at temperatures of 30 and $40^{\circ} \mathrm{C}$ ), the magnetic field accelerated the process of desorption.

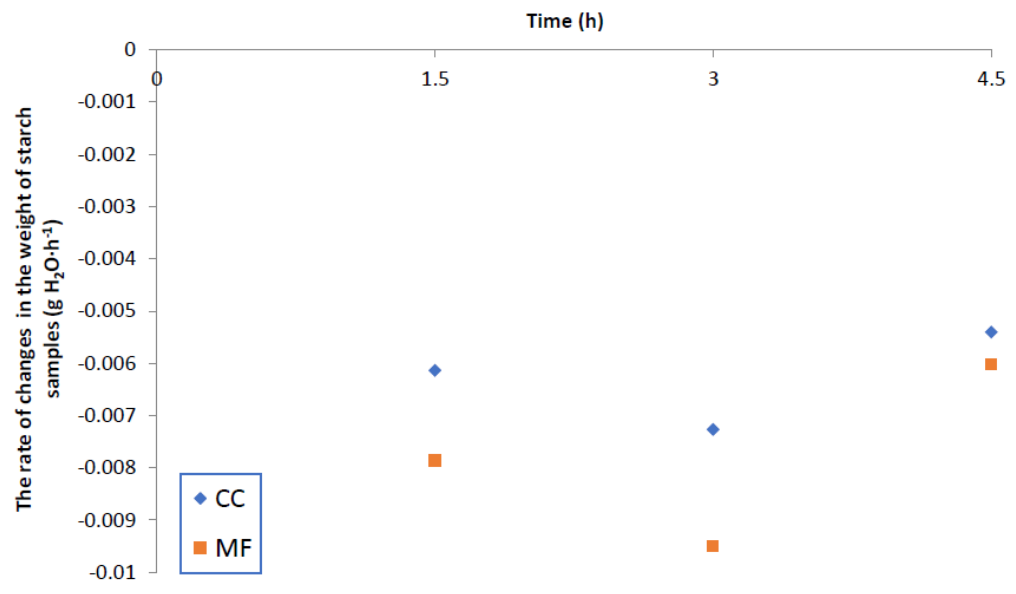

Fig. 4. The rate of change in the weight of starch samples depends on the desorption of water at $30^{\circ} \mathrm{C}$ under control conditions (CC) and stable magnetic field conditions (MF) 


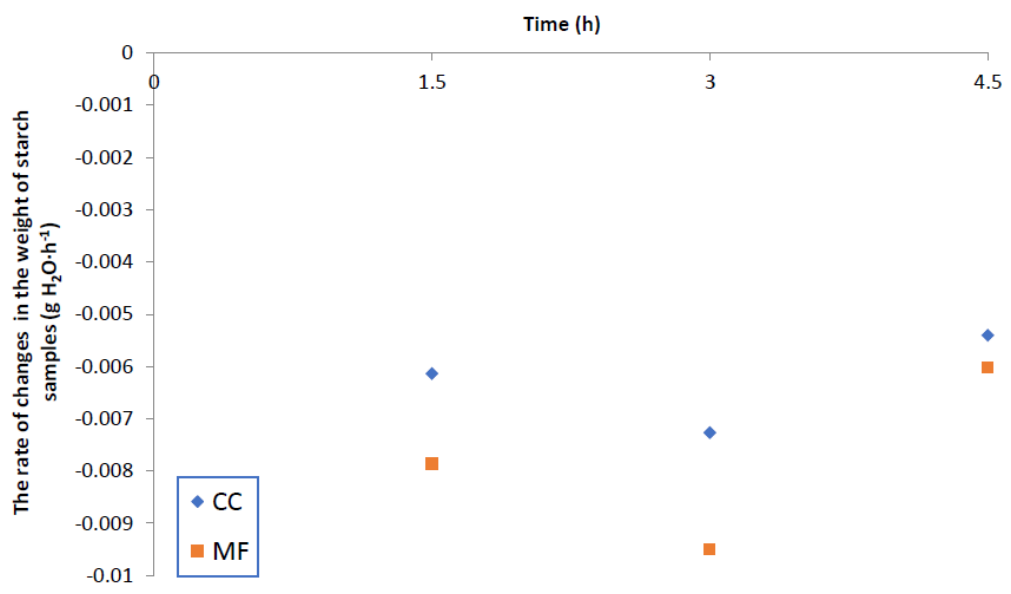

Fig. 5. The rate of change in the weight of starch samples depends on the desorption of water at $40^{\circ} \mathrm{C}$ under control conditions (CC) and stable magnetic field conditions (MF)

The process of desorption resulted in a sample weight decrease (Figs 6 and 7). In addition, the effect of the magnetic field was manifested by the system tending towards a new equilibrium state, which was different from the one which occurs under control conditions.

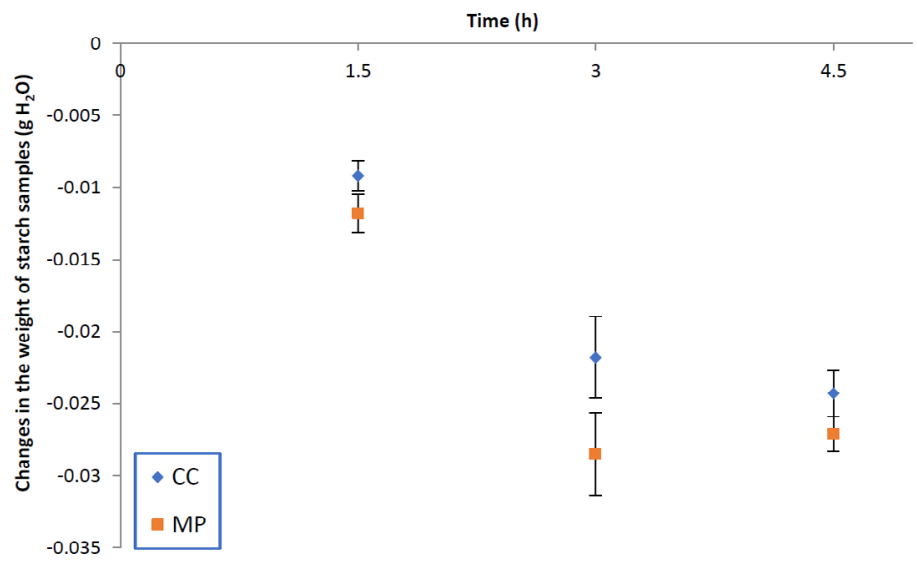

Fig. 6. Changes in the weight of starch samples over time as affected by water desorption at $30^{\circ} \mathrm{C}$ under control conditions (CC) and stable magnetic field conditions (MF)

While tending to reach a dynamic equilibrium, the starch samples placed in drying chambers and exposed to the effect of a magnetic field released larger amounts of water to the environment (in the same time intervals) compared to the samples placed in drying chambers under control conditions (Tab. 2) these amounts were statistically significant $(0.001<\mathrm{p}$-value $<0.05)$. 


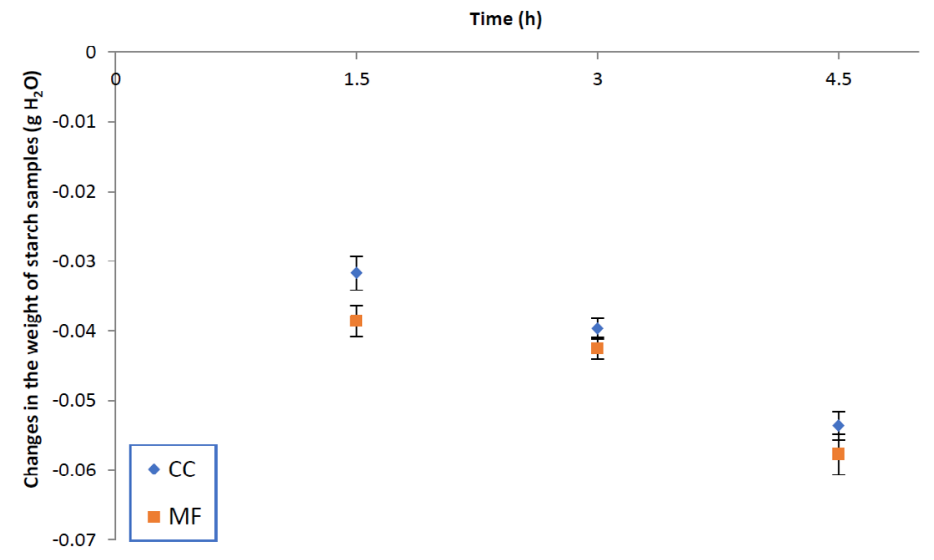

Fig. 7. Changes in the weight of starch samples over time as affected by water desorption at $40^{\circ} \mathrm{C}$ under control conditions (CC) and stable magnetic field conditions (MF)

Table 2. A statistical analysis of the differences between the average weight changes of samples stored under control conditions and under magnetic field conditions

\begin{tabular}{lllcl}
\hline \multirow{2}{*}{ Statistics } & \multicolumn{5}{c}{ Time $(\mathrm{h})$} \\
\cline { 2 - 5 } & 1.5 & 3.0 & 4.5 \\
\hline Test F & 0.5880 & $30^{\circ} \mathrm{C}$ & 0.9629 & 0.4905 \\
p-value & 0.0009 & & 0.0004 & 0.0015 \\
& & $40{ }^{\circ} \mathrm{C}$ & & \\
Test F & 0.7623 & & 0.9732 & 0.3761 \\
p-value & $3.5089 \mathrm{E}-05$ & 0.0025 & 0.0060 \\
\hline
\end{tabular}

The empirically confirmed effect was that the desorption process of water vapour from the surface of the tested samples differed in its kinetics and in its extent between the samples under control conditions and those under conditions stimulated with the magnetic field. Regardless of the measuring temperature, the process of desorption always proceeded with a greater intensity under the conditions of exposure to a magnetic field.

The pressure of water vapour in the starch samples probably increased as a result of their exposure to the magnetic field. Considering the above, a hypothesis was advanced that the stable magnetic field triggered changes in the thermodynamic state of the water molecules present in the potato starch, which promoted their vaporization and their escape to the environment with a lower vapour pressure. As a consequence of the assumptions presented, it may be hypothesized that the presence of the magnetic field was conducive to an increase in the entropy of the examined system.

The last stage of the study included a comparison of the extent of sorption under control conditions (CC) and conditions stimulated with a stable magnetic field (MF). Differences in the dynamic equilibrium state were described by comparing 
the water contents of the samples after their 4.5-hour exposure to the desorption process $\left(\mathrm{CC}_{30^{\circ} \mathrm{C}}=0.1646 \mathrm{~g} \mathrm{H}_{2} \mathrm{O} 100 \mathrm{~g}^{-1}\right.$ d.m. $\pm 0.0016 \mathrm{~g} \mathrm{H}_{2} \mathrm{O} 100 \mathrm{~g}^{-1}$ d.m.; $\mathrm{MF}_{30^{\circ} \mathrm{C}}=0.1618 \mathrm{~g} \mathrm{H}_{2} \mathrm{O} 100 \mathrm{~g}^{-1}$ d.m. $\pm 0.0012 \mathrm{~g} \mathrm{H}_{2} \mathrm{O} 100 \mathrm{~g}^{-1}$ d.m.; $\mathrm{CC}_{40^{\circ} \mathrm{C}}=$ $0.1353 \mathrm{~g} \mathrm{H}_{2} \mathrm{O} 100 \mathrm{~g}^{-1}$ d.m. $\pm 0.0021 \mathrm{~g} \mathrm{H}_{2} \mathrm{O} 100 \mathrm{~g}^{-1}$ d.m.; $\mathrm{MF}_{40^{\circ} \mathrm{C}}=0.1312 \mathrm{~g} \mathrm{H}_{2} \mathrm{O} 100 \mathrm{~g}^{-1}$ d.m. $\pm 0.0029 \mathrm{~g} \mathrm{H}_{2} \mathrm{O} 100 \mathrm{~g}^{-1}$ d.m.). The period of 4.5 hours was assumed to be sufficient to allow the examined system to reach a state of dynamic equilibrium. The statistical analysis of differences demonstrated that the extent of the desorption phenomenon, expressed as a decrease in sample weight after a 4.5-hour incubation at various temperatures, was always greater under magnetic field conditions $\left(\right.$ Test $\mathrm{F}_{30^{\circ} \mathrm{C}}=0.4905 ; \mathrm{p}$-value $30^{\circ} \mathrm{C}=0.0015 ;$ Test $\mathrm{F}_{40^{\circ} \mathrm{C}}=0.3761 ; \mathrm{p}$-value $\left.{ }_{40^{\circ} \mathrm{C}}=0.0060\right)$. It may therefore be concluded that the impact of a strong stable magnetic field caused a greater value of work within the system than the work performed under conditions of the absence of a magnetic field. Each time, an outcome of the work performed by the system was the migration of water molecules from the surface of the samples to the environment, which was indicated by a decrease in sample weight (Dutkiewicz 1998). Once the work had been completed, the system was in a different state than it was in before the work, because the weight of the samples had changed (Buchowski and Ufnalski 1998). Therefore, the work performed is indicative of energy that could derive from the magnetic field. Considering that, it should be stated that the energy associated with the presence of the stable magnetic field caused an increase in water vapour pressure in the samples tested. This energy enabled the breaking of hydrogen bonds that connect water molecules and their vaporization from the sample. Thus, it may be assumed that the stable magnetic field stimulated the system (drying chamber - sample) causing an entropy increase in the process of desorption proceeding on the surface of the analysed samples.

A stable magnetic field significantly affects the intensity of surface phenomena. Thus, there are arguments to suppose that the absence of a stable magnetic field, e.g. on the surface of the Moon, may contribute to a decrease in the intensity of surface phenomena that determine food stability compared to the characteristics recorded on Earth. At the same time, it may be speculated that the observed phenomenon may find a practical application in the design of dehydration devices, especially at low temperatures, that would facilitate the maintenance of a high quality of food.

\section{CONCLUSIONS}

The results of the conducted experiments indicate the influence of the magnetic field on the kinetics and extent of water desorption by potato starch. The magnetic field increases the value (extent) and rate (kinetics) of water desorption from the starch surface. The strong magnetic field causes the dynamic equilibrium state of the sample-atmosphere system to be set at a different, higher level than under 
conditions of no exposure to the magnetic field. The explanation for this process at the level of elementary phenomena (atomic or even molecular) is impossible to obtain at the current stage of research, and the likely mechanisms of the phenomenon presented in this work are based on macroscopic observations. The impact of the magnetic field is considered to be a decisive factor in changing the thermodynamic state of water molecules, leading to an increase in water activity.

The mechanism of the desorption process in the presence of a magnetic field is not fully understood and remains in the realm of the hypotheses described in this work. However, they are the starting points for research aimed at formulating grounds to enable the prediction of changes that occur in food stored under different conditions, even those different from the terrestrial ones. This may be important in the future with a growing interest in the exploration of extraterrestrial space.

Considering the results obtained, it may be assumed that the intensity of water desorption from food surfaces will be lower in the environment of a very weak magnetic field. In addition, this phenomenon should be studied in terms of its role in the effectiveness of the functioning of devices for the dehydration of products sensitive to high temperatures.

Conflict of interest: The Authors does not declare conflict of interest.

\section{REFERENCES}

Ambashta R.D., Sillanpää M., 2010. Water purification using magnetic assistance: A review. J. Hazardous Materials, 180(1-3), 38-49, https://doi.org/10.1016/j.jhazmat.2010.04.105

Buchowski H., Ufnalski W., 1998. Fundamentals of thermodynamics (in Polish), WNT, Warszawa.

Czerniawski B., Michniewicz J., 1998. Food packaging (in Polish), Agro Food Technology, Czeladź. Dutkiewicz E.T., 1998. Physicochemistry of surface (in Polish), WNT, Warszawa.

Fathi A., Mohamed T., Claude G., Maurin G., Mohamed B.A., 2006. Effect of a magnetic water treatment on homogeneous and heterogeneous precipitation of calcium carbonate. Water Research, 40(10), 1941-1950, https://doi.org/10.1016/j.watres.2006.03.013

Fey D.P., Greszkiewicz M., Otremba Z., Andrulewicz E., 2019. Effect of static magnetic field on the hatching success, growth, mortality, and yolk-sac absorption of larval Northern pike Esox Lucius. Sci. Total Environ., 647, 1239-1244, https://doi.org/10.1016/j.scitotenv.2018.07.427

Higashitani K., Oshitani J., 1996. Measurements of magnetic effects on electrolyte solutions by atomic force microscope. Proceedings of the $2^{\text {nd }}$ International Meeting on Anti-Scale Magnetic Treatment. Cranfield University, Bedfordshire, England.

Ji Y., Wang Y., Sun J., Yan T., Li J., Zhao T.T., Yin X.H., Sun C.J., 2010. Enhancement of biological treatment of wastewater by magnetic field. Bioresour. Technol. 101, 8535-8540, https://doi. org/10.1016/j.biortech.2010.05.094

Kędzierska-Matysek M., Matwijczuk A., Florek M., Kornarzyński K., Matwijczuk A., Wolanciuk A., Barłowska J., Gładyszewska B., 2018. Effect of magnetic field on 5-hydroxymethylfurfural content, diastase activity and changes in the ATR-FTIR spectra in raw buckwheat honey (in Polish). Przem. Chem., 97(3), 381-385. 
Lewicki P.P., Lenart A., Płaczek A., Skrzeszewski S., 1977. Kinetics of water vapor sorption by selected food products (in Polish) Przem. Spoż., 31(11), 428-432.

NASA potwierdza: Ziemia ma drugi, mniejszy Księżyc. Retrieved 08.10.2019 from https://www.crazynauka.pl/nasa-potwierdza-ziemia-ma-drugi-mniejszy-ksiezyc/

Ocieczek A., 2013. Impact of comminution on adsorption properties of gluten-free wheat starch. Acta Agroph., 20(1), 125-136.

Ocieczek A., Kostek R., Ruszkowska M., 2015. Kinetic model of water vapour adsorption by gluten-free starch. Int. Agrophys., 29(1), 115-119, https://doi.org/10.1515/intag-2015-0006.

Rahman M.S., 2006. State diagram of foods: Its potential use in food processing and product stability. Trends in Food Sci. \& Technol., 17(3),129-141, https://doi.org/10.1016/j.tifs.2005.09.009

Wang Y., Pugh R.J., Forssberg E., 1994. The influence of interparticle surface forces on the coagulation of weakly magnetic mineral ultrafines in a magnetic field. Colloids Surf. A., 90(2-3), 117133, https://doi.org/10.1016/0927-7757(94)02908-3

www.encyklopedia.pwn.pl., 2019. Księżyc. Retrieved 08.10.2019 from https://encyklopedia.pwn.pl/ haslo/Ksiezyc;3928465.html

www.esa.int 2019. Compete in a lunar economy. Retrieved 08.10.2019 from https://www.esa.int/ About_Us/Business_with_ESA/ESA_Grand_Challenge/Compete_in_a_lunar_economy

www.tech.wp.pl., 2019. Kolonizacja Księżyca rozpoczęta. Jedno państwo mocno w tym przoduje. Retrieved 08.10.2019 from https://tech.wp.pl/kolonizacja-ksiezyca-rozpoczeta-jedno-panstwomocno-w-tym-przoduje-6339070406067841a

www2.jpl.nasa.gov 2019. Asteroid watch. Retrieved 12.09.2019 from https://www.jpl.nasa.gov/ asteroidwatch/

Zhang H., Zhao Z., Xu X., Li L., 2011. Study on industrial wastewater treatment using superconducting magnetic separation. Cryogenics, 51(6), 225-228, https://doi.org/10.1016/j.scitotenv.2018.07.427 